\title{
Erratum to: Adoption of smart grid technologies by electric utilities: factors influencing organizational innovation in a regulated environment
}

Jason Dedrick • Murali Venkatesh • Jeffrey M. Stanton • You Zheng • Angela Ramnarine-Rieks

Published online: 31 October 2014

(C) Institute of Information Management, University of St. Gallen 2014

Erratum to: Electron Markets

DOI 10.1007/s12525-014-0166-6

The original version of this paper unfortunately misses the acknowledgment section which is below:

"This material is based upon work supported by the National Science Foundation under Grant No. SES-1231192."

The online version of the original article can be found at http://dx.doi.org/ 10.1007/s12525-014-0166-6.

J. Dedrick $(\bowtie) \cdot$ M. Venkatesh · J. M. Stanton · Y. Zheng •

A. Ramnarine-Rieks

Syracuse University, 324 Hinds Hall, Syracuse, NY 13244, USA

e-mail: jdedrick@syr.edu

M. Venkatesh

e-mail: mvenkate@syr.edu

J. M. Stanton

e-mail: jmstanto@syr.edu

Y. Zheng

e-mail: youzheng476@gmail.com

A. Ramnarine-Rieks

e-mail: auramnar@syr.edu 